\title{
Establishing drought-tolerant pasture species on east coast downlands by direct drilling
}

\author{
T.J. FRASER' and D.C. HEWSON ${ }^{2}$ \\ ${ }^{1}$ AgResearch, PO Box 60, Lincoln \\ ${ }^{2}$ Otago Regional Council, Private Bag, Dunedin
}

\section{A bstract}

Successful establishment of drought-tolerant pastures through direct drilling on erosion prone dry East Coast downlands can be guaranteed if some simple management practices are put in place. Pasture mixtures containing mainly Grasslands Wana cocksfoot, Grasslands Maru phalaris Grasslands Roa tall fescue and Grassland Tahora white clover were direct drilled into 450 ha on 60 paddocks in North Otago. Establishment of new pastures on paddocks that had been double herbicide treated prior to sowing (spray-fallow technique), were significantly superior to those treatments that only had a single spray prior to drilling. Correct sowing depth was made possible with the use of the Massey University bioblade direct drill. Its inverted ' $T$ ' coulter creates an underground cavort with sufficient tilth to provide an ideal microclimate for seedling establishment. The success of the programme is reflected in the fact that $50 \%$ of farmers involved have established new pasture by direct drilling since the programme was implemented, $93 \%$ intend establishing pastures by direct drilling in the future and $98 \%$ have sown, or intend to sow, pastures using alternative species to perennial ryegrass.

Keywords: direct drilling, drought-tolerant species, erosion, pasture establishment, spray-fallow technique, summer fallow

\section{Introduction}

The Otago Regional Council (ORC) has been concerned for many years about the serious rill erosion which frequently occurs when the downland soils are cultivated. Past attempts to reduce the problem have been largely ineffective, and potentially unsustainable farming systems have continued. The problem arises from two interactive causes. Frequent droughts result in failure of the commonly used ryegrass based pastures after 2-5 years. This means paddocks are frequently cultivated for regrassing, exposing the soil to the risk of erosion. The 1988 drought devastated many ryegrass pastures in the downlands, with the result that ORC was faced with the possibility of large areas being cultivated and exposed to erosion during regrassing operations.

Erosion destroys the soil's productivity on site while causing sedimentation, eutrophication and pollution in the river systems. Eroded soils are shallower and therefore more prone to drought. Furthermore, much of the North Otago area is loess downland where past erosion and cultivation has left very shallow topsoil. The shallow topsoil and compact subsoil have low moisture-holding capacities and deep rooting of plants is thus inhibited.

Sheet wash and rill erosion is by far the most serious form of soil loss from arable land in the North Otago area. It has been estimated that 50 times more soil is lost through rilling than from other forms of erosion. With almost every heavy rain event, some cultivated paddocks suffer moderate to severe rilling or sheet wash (ORC 1989).

Between January and March 1986 it is estimated that 240 ha on 24 properties lost an average of 50 tonnes/ha (i.e. $5 \mathrm{~mm}$ depth of topsoil). This is a total topsoil loss of 12000 tonnes, which would require fertiliser costing about $\$ 300000$ to replace just the major nutrients lost (ORC 1989).

Frequent cultivation results in a loss of organic matter and destruction of soil structure which increases the tendency to rilling. However, farmers regard rill erosion after heavy rain as bad luck, not inappropriate land management. Even though soil losses of up to 2.50 tonnes per hectare have been recorded, the devastation of severe rilling and drought are quickly forgotten during wetter seasons. Consequently, many farmers are not convinced\&at this soil loss is important or do not see that there are practical ways to overcome the problem.

The continuing severity of the 1988/89 drought provided the impetus to develop a package that would provide solutions to both drought and erosion. The approach taken was to design a project which would bring about a change in farmer attitudes to the problems by demonstrating a viable pasture establishment alternative to cultivation and to encourage dryland farming systems which work within the constraints of the area's dry climate. Technical advice for this programme came from a wide range of organisations, 
because none individually bad the expertise in all aspects (establishing new cultivars, chemical weed control, fertiliser requirements, direct drilling and pest control). The excellent co-operation between these organisations and farmer involvement was a feature of the programme. Organisations involved included DSIR Grasslands, Massey University, Agriculture New Zealand, Ravensdown, Monsanto, Coated Seeds and Skinner Seeds.

\section{Aims}

(a) Assist and promote direct drilling to renew pastures on erosion prone rolling downlands, thereby reducing the erosion risk.

Direct drilling was seen as the only practical way of regrassing the downlands without erosion. In the past direct drilling has been promoted as a cheap option and many farmers have tried it with poor results. Consequently, there was considerable farmer scepticism towards the programme. To reduce the risk of further failures, ORC made available the most advanced direct drill technology (Massey bioblade drill) and provided the best available technical advice.

(b) Encourage use of new dryland pasture species on steeper downlands to maintain persistent vegetative cover and reduce erosion.

The use of new drought- and pest-tolerant pasture species which would give better ground cover and last longer, removing the need for regular cultivation (and consequent erosion). Although these new grasses had been available for a number of years, few farmers had sown them and they had not been direct drilled to any extent.

\section{Methods}

Sixty paddocks were drilled on 56 properties (total area $450 \mathrm{ha}$ ), in the North Otago area. Main criteria for selection were:

1. land with potential for wind, rill or floodwater erosion.

2. steeper class IV land, up to $22^{0}$ slope.

3. sunny aspect.

Because of these criteria most of the land drilled tended to be at the lower end of land quality. Farmers were financially responsible for herbicide treatment, seed, fertiliser and insecticide, ORC was responsible for costs of project management, direct drilling and technical advice on pasture seed mixtures and management.
All paddocks were visited and soil was sampled prior to the start of the programme. Individual seed mixtures were recommended in consultation with the farmer, taking into account the physical aspects of the paddock and the farmer's long-term management aims. Each paddock received its own fertiliser recommendation.

As the main aim of this programme was to show that persistent pasture species could be successfully established by direct drilling under harsh environments it was important to adhere to some simple established principles for regrassing.

\section{1. fine firm seed bed.}

2. adequate moisture.

3. correct soil fertility for chosen species.

4. correct sowing time and depth.

While it is relatively easy to achieve these conditions with conventional cultivation, past experience has shown that in most cases they are difficult to achieve with direct drilling. The inability to create these conditions has been the main cause of failures relating to direct drilling. The development of the Massey University bioblade drill has meant that seed can be sown at the correct depth into sometimes uneven surface conditions because of the individual seeder depth control technology of this drill. A further advantage of the Massey drill is the 'winged openers' that create good soil tilth where the seed is placed thus mimicking the conditions of a cultivated seed bed.

The problem of adequate soil moisture for autumn sowing in drought areas is overcome with summer fallow using conventional cultivation methods. To try to simulate these conditions with direct drilling a spray fallow technique was put in place on most paddocks. This involved herbicide spraying in late spring with a follow up second spray prior to drilling in autumn. This spray regime was intended to kill all vegetation which would otherwise deplete soil moisture reserves. The amount and type of chemical used depended on the existing vegetation. In some cases only a single herbicide spray was applied (single spray) just prior to drilling. The main reason for this was the reluctance of the farmers concerned to double up on the spray cost or their conservative attitude to change.

Seed mixtures were specific to individual paddocks, but in most cases were dominated by Grasslands Wana cocksfoot (Dactylis glomerata), Grasslands Maru phalaris (Phalaris aquatica), Grasslands Roa tall fescue (Festuca arundinacea) and Grasslands Tahora white clover (Trifolium repens). These species predominated because most of the paddocks were difficult harsh sites and the requirement for the pastures, once established, 
was to give persistence and ground cover. Pasture quality was a secondary consideration.

Insects and pests were monitored before and after drilling and appropriate action taken if numbers were potentially dangerous to establishing new pastures. Insecticide was applied at sowing to control grass grub and slugs if required. Three grass grubs per spade at drilling was the trigger point for chemical application. Slugs were controlled by trampling with 1200 sheep per ha for 24 hours just prior to drilling. Most pastures were sown during autumn 1990, with the remainder in spring 1990.

Visual scoring (1-10 best) for establishment ground cover, \% sown species, \% weeds etc. was done 4-6 weeks after drilling. This was followed up in 1993194 (year 4) with a score for persistence, ground cover, \% sown species and general vigour of the pastures. The 56 farmers involved were questioned ( 5 years after drilling) on their perception of the success or failure of their pastures, their attitude to direct drilling and their use of alternative pasture species.

\section{Results and discussion}

\section{Spray treatments}

The advantage of double spray over a single pass is clearly shown in Table 1. With two sprays there were few failures and a high percentage of paddocks in the good to excellent range. There are two main reasons for this: a better kill of the existing vegetation because the pasture was still actively growing at the time of spraying and the conservation of moisture available in the top 20 $\mathrm{cm}$ due to the summer fallow (Table 2). Across a range

-of-paddocks-there-was-12-times-the-moisture-in-double sprayed treatments compared with single sprayed. This clearly demonstrates the importance of summer fallowing and shows that this can be achieved with herbicide treatments if applied prior to the onset of summer moisture stress. The extra moisture retained with the spray fallow technique allowed earthworms to remain active longer speeding up organic matter breakdown. Such differences in plant-available soil water content at the time of direct drilling in late summer to mid-autumn are likely to have a major influence on plant estäblišsment, and on growth before winter.

Table 1 Influence of number of herbicide treatments on pasture establishment. Number of paddocks at and ranking four years after sowing.

\begin{tabular}{ccccccc}
\hline $\begin{array}{c}\text { Number of } \\
\text { Sprays }\end{array}$ & Failure & Poor & Average & Good & Excellent & All \\
\hline 1 & 2 & 1 & 3 & 7 & 2 & 15 \\
2 & 1 & 2 & 5 & 15 & 16 & 41 \\
All & 3 & 3 & 8 & 22 & 20 & 56 \\
\hline
\end{tabular}

Table 2 Plant available soil moisture $(\mathrm{mm})$. Mean of five sites.

\begin{tabular}{rccc}
\hline Soil depth $(\mathrm{cm})$ & Unsprayed & Sprayed & $\begin{array}{c}\text { Coefficient of } \\
\text { variation } \%\end{array}$ \\
\hline $0-20$ & 2.4 & 26.0 & 22.6 \\
$0-30$ & 10.6 & 55.0 & 23.0 \\
\hline
\end{tabular}

\section{Perceived site quality}

At initial inspection all paddocks were assessed for ease. of establishing new pastures. Aspect, contour, slope, soil type and fertility were taken into account and paddocks were classified as easy, medium or hard. Soil test results indicated that on average the area to be sown was in the low to medium fertility range. Average reading being $\mathrm{pH}$ 5.7, phosphate 10 and sulphur 5 .

There was little difference between paddock scores at establishment and at final score (Table 3). However there was a tendency for average paddocks to improve with time. This emphasises the importance of successful establishment for long term vigour of pastures, it is difficult to turn a poor establishment into a good, high producing pasture.

Table 3 Pasture establishment. Paddock scores with final score in brackets

Perceived Failure Poor Average Good Excellent Al site quality

\begin{tabular}{lllllll}
\hline Easy & $2(2)$ & $2(2)$ & $2(4)$ & $7(6)$ & $3(2)$ & 16 \\
Medium & $0(1)$ & $0(0)$ & $4(1)$ & $6(9)$ & $3(2)$ & 13 \\
Hard & $0(0)$ & $1(1)$ & $10(3)$ & $7(7)$ & $9(16)$ & 27 \\
All & $2(3)$ & $3(3)$ & $16(8)$ & $20(22)$ & $15(20)$ & 56 \\
\hline
\end{tabular}

At final score $88 \%$ of the paddocks on the hard sites and only 55\% on the easy sites scored above average. This is probably the most important message from this programme. On the hard sites, land preparation tended to be more precise; a higher percentage of these paddocks were double sprayed and greater effort went into making sure all aspects of drilling depth were correct. This reflected the desire not to have to redrill these paddocks for a very long time. On the easier sites there was a tendency to-think-that the betterconditions and fertility could allow short cuts to be made.

\section{Farmer involvement}

One of the aims of this programme was to make farmers more aware of drought-tolerant species and give them confidence to direct drill these species on their properties. Farmers were surveyed at the end of year 4 for their evaluation of pastures sown in the programme and their subsequent pasture-renewing programmes. 
The farmers' score of established pastures tended to be similar and consistent with those recorded by the authors. The main drawback expressed by the farmers was that in some instances the new pastures were less palatable than the ryegrass pastures they were more used to. It is still of some concern that farmers believe that it is possible to have persistent pastures that will give high quality herbage throughout the year. The areas sown in this programme were all at risk from erosion and the stated aim was to give long-term, persistent ground cover. Quality herbage for animal finishing should be grown on the easier, high fertility areas of the farm.

\section{Farmer uptake}

The very high degree of farmer acceptance and use of direct drilling as a means of establishing new pastures (93\%) shows the success of the programme in demonstrating this management practice (Table 4). In all cases the farmers recognised the importance of the double- spray technique. The total acceptance of the value of alternative species reflects the awareness of farmers in the North Otago area of the value of these pastures.

Table 4 Farmer uptake since start of programme.

\begin{tabular}{lccc}
\hline & Yes & 0 & $\%$ Uptake \\
\hline Have direct drilled since programme & $\mathbf{2 8}$ & $\mathbf{2 8}$ & $\mathbf{5 0}$ \\
Will direct drill in the future & $\mathbf{5 2}$ & $\mathbf{4}$ & 93 \\
Have sown alternative species & $\mathbf{4 5}$ & $\mathbf{1 1}$ & $\mathbf{8 0}$ \\
$\begin{array}{l}\text { Will sow alternative species in the } \\
\text { future }\end{array}$ & 55 & 1 & 99 \\
\hline
\end{tabular}

\section{Conclusion}

Establishing new pastures by direct drilling can be successful under even the hard conditions provided some simple management practices are put in place. The aim is to make conditions as near as possible to conventional cultivation and this will be achieved by using:

1. the double spray technique.

2. a suitable drill that gives good depth control and creates some form of soil tilth.

3. the correct selection of species.

4. the correct time of sowing.

5. pest control both pre and post drilling if necessary.

It is important not to think of establishing new pastures by direct drilling as being a cheap option. For results that are at least as good as those for establishing pastures by conventional cultivation, costs and time out of production will be similar.

The advantages of direct drilling on the dry downlands are long term, in that soil is conserved, allowing for continuing farming output from these areas, this is an option that will not be available if the present cultivation practices are continued.

The uptake of alternative species by the farmers in this programme was very high. Eighty percent have used species other than the conventional ryegrass pastures, and all the farmers involved intend to use alternative species in the future.

\section{REFERENCES}

Otago Regional Council 1989. Report 89/59. 